\title{
The Progress of Non-Profit Organization Accounting Studies
}

\author{
Li ChunHua \\ International Education Institute of Beijing Vocational College of Agriculture
}

\begin{abstract}
In order to solve the focus questions studied both at home and abroad about non-profit organization accounting, the writer adopts comparative analysis method, defines the range of non-profit organization in our country and confirms the accounting goal. It has been explained that non-profit organization accounting in our country should adopt the accounting mode of the fund for special use. Which system that non-profit organization accounting in our country belongs to is summarized. The paper has put forward the idea of designing the accounting criterion system of non-profit organization. The problems that non-profit organization accounting in our country exists and the future research direction have been analyzed in this paper.
\end{abstract}

Keywords—non-profit organization, accounting, accounting model, criterion system

\section{非营利组织会计研究进展}

\author{
李春华 \\ 北京农业职业学院国际教育学院
}

摘 要 为了解决国内外对非营利组织会计研究的焦点问题, 笔者采用比较分析法, 界定了非营利组织的范围, 确定了我国非营利 组织会计目标，阐述了我国非营利组织会计应采取专用基金会计模式，综述了我国非营利组织会计归属体系问题，提出了设计非营利 组织会计准则体系的构想, 分析了我国非营利组织会计存在的问题及未来研究方向。

关键词 非营利组织, 会计, 会计模式, 准则体系

\section{1. 非营利组织的界定}

美国财务会计准则委员会根据与营利组织的对比, 将 非营利组织定义为“符合以下特征的实体: (1)该实体从捐赠 者处获得大量的资源, 但捐赠者并不因此而要求得到同等 或成比例的资金回报; (2)该实体经营的目的并不是为了赚 取利润; (3) 该实体不存在营利组织中的所有者权益问 题。”[1]非营利组织的范围非常广泛, 既包括大型组织, 如 美国红十字会, 也包括小型组织, 如宗教组织、卫生和福利 机构、教育机构等, 非营利组织的特征是非营利组织的“志 愿性”、“公益性”[2]。

我国《民间非盈利组织会计制度 (征求意见稿)》指出 民间非营利组织应符合以下条件：不以营利为目的；任何 单位和个人不因为出资而拥有非营利组织的所有权, 收支

[基金项目] 北京农业职业学院专业带头人培养计划资助项目
结余不得向出资者分配; 非营利组织一旦进行清算, 清算 后的剩余财产应按规定继续用于社会公益事业 ${ }^{[3]}$ 。此定义 借鉴了美国的定义, 且更加突出了非营利性和社会公益目 的。

我国的非营利组织可定义为：不以营利为目的，资财 供应者不图回报，其剩余资财不存在明确的所有者权益的 组织或单位。非营利组织包括公立非营利组织和民间私立 非营利组织, 具体包括社会团体、卫生和福利机构、教育 机构、基金会和民办非企业单位等。

\section{2. 非营利组织会计目标}

非营利组织会计目标是指非营利组织提供财务信息的 目标, 或财务报表目标。西方明确提出了政府与非营利组 织会计的具体目标, 而我国对此没有作具体规定。我国目 前的预算会计规范主要针对具体业务的会计处理, 而没有 
专门发布公告就预算会计目标作出完整的阐述。因此, 研 究非营利组织会计目标是非常必要的。

\section{1 西方非营利组织会计目标的研究成果}

西方国家的研究可归纳为三个方面：(1) 谁是财务信 息使用者。非营利组织财务信息使用者一般可分为立法机 关或其他统治团体、公众、投资者、贷款人、其他非营利 组织、其他资源提供者及管理人员等。(2) 他们需要什么 样的信息。财务信息使用者一般需要管理的信息、财务状 况信息、业绩信息以及经济影响的信息等。（3）财务报告 能够提供什么信息。美国财务会计准则委员会 (FASB) 在 《非营利组织编制财务报告的目标》中指出, 非营利组织 会计报告的基本目标就是向资财供给者和其他信息使用 者, 在分配资财给非营利组织做出合理决策时提供有用信 息; 另一方面, 提供管理人员如何履行经管责任的信息 ${ }^{[4]}$ 。 并围绕经管责任列示了七项具体目标: 财务报告应向现在 和潜在的资财供给者和其他用户, 在分配资财给非营利组 织做出合理决策时提供有用信息; 提供有助于评估某一非 营利组织所供服务及其持续提供这些服务能力的信息; 提 供为评估某一非营利组织的管理人员履行其操持经营责任 和其他方面业绩有用的信息; 提供关于某一非营利组织的 经济资源、债务和净资产, 以及各种交易事项对这些方面 变动的影响的信息; 提供报告期内的业绩信息; 提供如何 获取和使用现金或其他流动资产、借款及其偿还, 以及可 能影响资产流动性的信息; 应当列示有助于使用者理解财 务信息的说明和解释。

\section{2 我国非营利组织会计目标的确定}

根据我国特定的社会、政治和经济环境, 考虑并借鉴 国外有关非营利组织会计目标的研究成果, 可以确定我国 的非营利组织会计目标: (1) 我国的非营利组织应为各级 人民代表大会及其代表、国家各级审计机关、服务对象、 纳税人、资源捐赠者、财政部门和上级单位提供财务信息。 (2) 我国非营利组织财务信息使用者需要的主要信息包 括: 资财分配使用的信息、估价劳务和评价劳务能力的信 息、评估管理当局业绩和经营责任的信息, 以及关于经济 资源、债务、净资产及其变动的信息等。（3）我国非营利 组织的财务报告应包括资产负债表、收入支出表、基建投 资表、附表及会计报表附注和收支情况说明书等。资产负 债表反映非营利组织某一时日拥有的资产和承担债务的情 况; 收入支出表反映非营利组织在某一时期的收入和支出 以及收支相抵后结余的情况; 基建投资表反映各方面投入 资金的使用情况及其效益[5]; 附表及会计报表附注和收支
情况说明书是对上述报表的补充和说明。可见, 在会计的 根本目标方面, 非营利组织会计和政府会计、企业会计是 有共性的, 但在具体内容上, 仍有较大的差别。

\section{3. 非营利组织专用基金会计模式}

\section{1 非营利组织专用基金会计模式}

从国外非营利组织会计模式分析, 非营利组织的财务 资源主要来自外部的捐赠, 也有政府拨款, 由于这些财务 资源的捐赠人可能规定财务资源的特定用途或限制条件， 使非营利组织承担了一定的受托经济责任, 英美等国建立 了与财务资源相适应的非营利组织基金会计模式。美国的 政府会计和公立非营利组织会计都采取基金会计模式[6]。 其特点是每一类“基金” 都是一个独立的会计主体，拥有自 己的资产、负债、收入、费用或支出、基金余额[7]。每一 种基金各自形成一套自动平衡帐户，优点是可以达到控制 和检查限定资源的使用是否符合法律和行政的要求, 但缺 点是基金种类多会使会计科目及会计报表都比较复杂, 各 基金之间的转帐也比较复杂, 且各项基金不能调剂使用, 使单位财力形成浪费。

我国不宜照搬国外的基金会计模式，应结合我国过去 专用基金核算经验, 吸收国外基金会计模式的精髓, 建立 一套适合我国国情的专用基金会计模式。国有非营利组织 和私立非营利组织都具有公共事业和产业的双重属性, 均 可采用专用基金会计模式，考虑到它们各自偏重的属性不 同，所设置的基金种类也不同。每一专用基金并非是独立 的会计主体, 每一个非营利组织才是独立的会计主体和报 告主体。采取这种会计模式, 既发挥了国外基金会计模式 的长处, 又没有国外基金会计模式的繁琐，符合我国国情。

非营利组织会计中的净资产一般由各种基金余额(FB: Fund Balance)构成, 基金(Fund)在西方非营利组织会计中有 着特定的含义, 基金可由法律条款、契约等来建立, 也可由 特别捐款来建立。基金通常由一个基金群(Fund Groups)来 构成, 基金群(Fund Groups)分为一般基金(未受限制的基 金)(General Fund)、限制基金(Restricted Fund)、留本基金 (Endowment), 限制基金又分为特殊目的(Specific Purpose)、 时间限制 (Time Restricted)、厂房重置和扩充 (Plant Replacement and Expansion)。因此, 非营利组织的会计主 体一般可包括三类:（1）永久限定用途基金。即非营利组 织在使用这些资金时, 要永久受提供者所附条件的限制;

（2）暂时限定用途基金。非营利组织在使用这些资金时, 要受提供者所附条件的限制, 但所附条件是暂时的; (3) 未限定用途基金。非营利组织在使用这些资金时，不受提 供者所附条件的限制, 只受来自组织的性质、规章制度, 
或在业务过程中订立的合同协议等的约束。将基金作为非 营利组织会计核算的主体, 充分体现了基金提供者的意愿, 也体现了非营利组织在资源管理上的重要特点——专款专 用。但是, 非营利组织在对外提供财务报表时, 必须以非 营利组织掌管的全部基金为一个整体来加以报告。

\section{2 我国非营利组织基金会计模式构建的基本思路}

按照《会计法》和《预算法》的要求, 借鉴外国政府 与非营利组织会计的先进经验, 结合我国改革的实践, 制 定基金会计准则或制度, 以规范基金会计核算, 实现非营 利组织的基金会计模式。实现这一目标, 可分两步完成: 一是以法规制度规范基金会计。即在现有预算会计模式运 行下，制定“基金管理办法”和“基金会计制度”，对基金从 管理和核算两个方面予以规范，明确基金的种类、原则、 基金会计要素、会计基础、核算程序和方法、基金会计报 表的编制等内容。目前采用这种模式比较符合实际, 关于 核算主体问题，可将基金作为政府及非营利组织“大会计主 体”下的“小会计主体”来处理。二是以准则规范基金会计。 即构建我国非营利组织会计准则框架，明确基金会计的规 范要求, 实现非营利组织基金会计模式, 与国际会计惯例 相协调。

\section{4. 非营利组织会计应归属的体系}

目前我国非营利组织已逐步走向市场，其资金来源已 日趋多元化, 自筹资金在其资金来源中占有相当大的比重, 但我国所有非营利组织仍统一执行由财政部制定的会计制 度, 这种对各类非营利组织不加区分的会计制度, 已不适 应非营利组织发展的需要。美国私立非营利组织会计尽管 原则上执行 FASB 发布的会计准则[8], 但 FASB 至今并未 为其制定一套符合其实际情况的会计准则, 在美国, 政府 会计与企业会计显然分属于两大会计体系, 但非营利组织 会计应当归属于哪个会计体系或者是否应当独立成为一个 会计体系也成了一个问题, 目前我国关于非营利组织会计 归属体系问题也有一些争论。

\section{1 非营利组织会计应归属于预算会计（政府会计）体系}

持这种观点的人认为, 公立非营利组织会计一直属于 预算会计体系, 如果分离出去, 会打乱中国多年来建立起 来的预算管理体系。

\section{2 非营利组织会计应当归属于企业会计体系}

持这种观点的人认为, 根据党中央提出的“面向社会, 走向市场, 减员增效, 减拨经费, 三年到位”, 以及非营利组
织也需要 “自负盈亏”, 非营利组织的经济效益指标将越来 越重要, 非营利组织的会计核算也将逐渐从以核算预算执 行情况为主转向全面核算非营利组织本身的经济效益为 主。企业会计中的诸多原则如权责发生制原则、配比原则、 收入实现原则等也将越来越多地适用于非营利组织, 非营 利组织会计将逐渐向企业会计靠拢, 而不是向预算会计靠 拢。

\section{3 非营利组织会计应成为一个相对独立的会计体系}

非营利组织会计既不应归属于企业会计体系，也不应 归属于预算会计体系, 即企业会计、预算会计(或政府会计)、 非营利组织会计各自成一体系。持这种观点的人认为, 非 营利组织以其不以营利为目的而区别于企业, 又以其不具 有社会管理职能而区别于政府。非营利组织会计需要核算 的是收支结余而不是利润，是净资产而不是所有者权益; 同时, 非营利组织会计也需要采用资本保持概念, 需要进 行成本核算、采用权责发生制基础 ${ }^{[9]}$ 。另外, 非营利组织存 在着众多的行业, 例如高等学校、中小学、科研院所、文 化馆、博物馆、医院、广播台、电视台等等, 非营利组织 会计应当成为一个相对独立的会计体系, 以满足其会计工 作特殊性的需要。

\section{4 非营利组织应分别纳入预算会计体系和企业会计体系}

公立或国有并且是非企业化管理的非营利组织纳入预 算会计体系, 私立以及企业化管理的国有非营利组织纳入 企业会计体系。中国的非营利组织数量庞大, 不仅区分成 公立和私立，而且还区分成企业化管理和非企业化管理。 中国的非营利组织将在近几年内发生巨大的变革, 大量的 文化非营利组织、运用型科研非营利组织、卫生非营利组 织、广播电视非营利组织等将全面走向市场, 实行企业化 管理。纳入预算会计体系的非营利组织, 可以仅限于那些 公立或国有并且是非企业化管理的非营利组织, 至于那些 私立以及企业化管理的国有非营利组织, 可以考虑不纳入 预算会计体系, 而纳入企业会计体系。这样, 中国的会计体 系依然由企业会计体系和预算会计体系两部分组成。

\section{5 单独建立私立非营利组织会计体系}

笔者认为, 私立及不纳入预算管理的非营利组织、社 会团体以及各种基金会计等应共同构成一个与企业会计、 预算会计 (政府会计) 相并列的私立非营利组织会计体系, 把公立且纳入预算管理的非营利组织会计纳入预算会计 （政府会计）体系。笔者不赞成将我国全部非营利组织会 计设为与企业会计、政府会计相并列的第三个相对独立的 
会计体系, 原因主要是: 一方面, 在中国的非营利组织中, 有的为国有或公立, 有的为私立, 有的是企业化管理, 有 的是非企业化管理, 各种非营利组织的情况各不相同, 要 想将我国非营利组织会计设立为一个相对独立的会计体系 几乎不大可能, 而建立具有中国特色的具体包括财政总预 算会计、行政单位会计以及公立且纳入预算管理的非营利 组织会计的政府会计体系, 符合中国的实际情况。

\section{5. 建立非营利组织会计准则体系}

美国在非营利组织会计准则方面, 除了明确区分成公 立和私立外, 没有一套可以适用于全部非营利组织的统一 会计准则[10][11], 即便是公立或者私立非营利组织统一的 会计准则也没有。实际中, 美国公立非营利组织执行由美 国政府会计准则委员会制定的非营利组织会计准则, 私立 非营利组织则适用于财务会计准则委员会制定的会计准 则; 而日本由政府有关部门分别制定了公立非营利事业会 计制度和民间非营利事业会计制度。可见, 美国和日本在 制定会计准则时, 都考虑了公立和私立非营利组织各自的 特殊性, 我国《非营利组织会计问题研究》课题组在借鉴 美国非营利组织会计准则体系的基础上, 提出了改革我国 事业单位会计准则的思路: 对于继续主要依靠财政拨款并 纳入预算管理的国有事业单位, 其会计规范仍执行现行的 事业单位会计制度; 对于事业单位, 应单独制定《非营利 组织会计制度》予以规范。

笔者认为, 对于非国有事业单位, 应单独制定《私立 非营利组织会计制度》予以规范, 课题组将国有事业单位 和非国有事业单位分别进行会计规范是符合国际惯例的, 但应根据私立事业单位具有非国有公共事业和产业双重性 质制定私立非营利组织会计准则, 形成我国三大会计准则 体系, 即具有国有公共事业性质的政府会计准则、具有产 业性质的企业会计准则和具有非国有公共和产业双重性质 的私立非营利组织会计准则。

借鉴国外的经验和我国企业会计准则制定中的成功做 法, 有学者提出应构建“两级准则层、三个准则群”的会计模 式。所谓两级准则层, 是将整个非营利组织会计准则体系 分为基本准则和具体准则两个层次, 其中, 基本准则是各 级非营利组织进行会计核算所共同遵守的基本规范, 具体 准则是非营利组织进行具体业务会计核算及报告揭示的具 体操作规范。所谓三个准则群, 是将整个会计准则体系分 为基本准则、通用业务准则、特殊行业和特殊业务准则三 个群体。基本准则群包括: 制定目的和适用范围, 确定基 本前提和基本会计假设，提出会计核算的一般要求，确认、 计量、记录、报告会计要素及提供信息等; 通用业务准则 群由若干条通用具体准则组成, 包括资产会计准则、负债
会计准则、净资产会计准则、基金会计准则、业务收支会 计准则、成本会计准则和基本会计报表准则等; 特殊行业 和特殊业务准则群由若干条特殊具体准则构成, 包括预算 和决算会计准则、国库会计准则、福利会计准则、捐赠会 计准则、基金会计准则、合并会计报表准则、汇总会计报 表准则等。

\section{6. 非营利组织会计存在的问题及未来的研究方向}

随着我国会计改革力度的加大，中西方非营利组织会 计在会计体系、会计准则、会计方程式、会计报表等方面, 较好地实现了与国际会计惯例的接轨, 但还存在一些问题。

\section{1 非营利组织会计要素的确认问题}

随着《国家赔偿法》的实施, 非营利组织将会面临许 多潜在的债务问题, 但非营利组织会计对或有负债没有予 以确认，而且现行非营利组织会计只确认当期实际收支的 债务, 对尚未到期的债务(包括政府债券和国外借款等)也 未予以确认, 这不利于强化非营利组织的受托责任, 也不 便于财务报告使用者了解国家债务情况。另外, 非营利组 织会计对许多属于国家和政府的权利均未予以确认、记录 和报告，如上级政府应补助款、我国政府在国际组织中的 权益, 以及权益属于国家而委托非营利组织管理的国有资 产产权等。国有资产产权及其变动情况尤其应在非营利组 织会计中予以记录和报告, 这是保护国有资产的一种有效 方法, 今后应注重研究这些要素如何确认的问题。

\section{2 非营利组织的会计核算基础问题}

随着预算会计环境的变化, 收付实现制出现了许多局 限性，如对非现金交易引起的债权债务不确认，无法提供 决策需要的会计信息, 也不利于反映政府及事业单位的受 托责任, 不能为非营利组织内部管理提供真实、有效的会 计信息。目前, 我国非营利组织改革按照国务院的有关设 想, “除教育单位和极少数需要由财政拨款的单位外, 其他 单位每年减少财政拨款 $1 / 3$, 争取三年基本达到自负盈亏”。 非营利组织的会计核算基础也将由以考核预算收支为主的 收付实现制逐渐转向以考核经济效益为主的权责发生制。 因此, 笔者认为非营利组织会计可采用修正的收付实现制, 即原则上采用收付实现制, 对某些特定业务则采用权责发 生制, 我国应分步推行非营利组织会计的核算基础, 由目 前修正的权责发生制向完全的权责发生制转化。

\section{3 非营利组织的成本核算问题}

目前的非营利组织会计一般仅提供支出信息，不实行 成本核算，无成本信息。支出类科目设立明细科目，可反 
映出支出的具体情况, 但却不能反映其劳务和服务成本, 不利于组织内部的核算与管理。随着非营利组织走向市场, 非营利组织会计实行成本核算非常必要。进行人才成本核 算有人提出可参照采用企业的“制造成本法”, 将费用划分 为直接费用和间接费用。直接费用直接计入成本核算对象, 间接费用按照一定的标准分配计入成本核算对象, 期间费 用(如财务费用、管理费用等)直接列入当期支出, 这种“制 造成本法” 是否真正适用于非营利组织的成本核算, 还有待 于进一步的研究与实践检验。

\section{4 非营利组织会计信息提供问题}

目前非营利组织会计缺乏提供资财分配使用的信息, 非营利组织的资财提供者虽不要求经济利益上的回报, 但 对资财的投向、使用和收回等方面还是非常关注的, 目前 的财务报告很少提供这方面的信息, 另外, 我国事业单位 会计报表包括资产负债表、收入支出表、基建投资表、附 表及会计报表附注和收支情况说明书等, 西方非营利组织 会计报表一般包括四种：一是财务状况表 (Statement of Financial Position), 相当于我国的资产负债表; 二是经营表 (Statement of Operations)相当于我国的收入支出表; 三是净 资产变动表(Statement of Changes In Net Assets); 四是现金 流量表(Statement of Cash Flows)。相比之下, 我国没有净资 产变动表和现金流量表, 以后也应加强这方面的信息研究, 以提供全面、有效的信息资料。

\section{参考文献(References)}

[1] Shu Huihao, Wang Peng. Learning foreign successful experience to promote the Chinese government and nonprofit organization accounting reform. Accounting Research, 2002, (5): $53 \sim 56$
[2] Zhang Lianjiang. Analysis of non profit organization accounting of. Accounting Monthly. 2003, B (5): 15 16

[3] Yuan Jian, He Fangying. The interpreting of "The folk non profit organization accounting system". Accounting Monthly. 2003, B (11): $57 \sim 58$

[4] Yuan Shuilin. Research on non profit organization accounting goal. Journal of Shanxi University of Finance and Economics, 2002, 24 (1): $97 \sim 99$

[5] Zhao Jianyong, Qi Yanxia. "The government and nonprofit organization accounting”.Fudan University Press, 2005 (1)

[6] Shi Yiqiao. Comparison of Chinese and American Government and Nonprofit Organization Accounting and accounting reform revelation in our country. Economic research Reference , 2010, 23: $62 \sim 64$

[7] Liu Jibin. The abstract interpretation of western government and non-profit organization accounting. Beijing: China financial and Economic Press, 2006

[8] Zhou Hong. International accounting standards 2000. Liaoning: Dongbei University of Finance and Economics press, 2008,3

[9] Li Chunhua, Li Chunjie, Chu Ying, Yang Hongbo. Study of construction of non-profit organizations accounting system. $2010(1)$

[10] Freeman and shoulders. Governmental and Nonprofit Accounting--Theory and Practice. Prentice-Hall, 1996.

[11] Governmental Accounting Standards Board (USA). Codification of Governmental Accounting and Financial Reporting Standards as of June, 1999. 